\title{
Immediate effects of first-line thrombectomy devices for intracranial atherosclerosis-related occlusion: stent retriever versus contact aspiration
}

Joonsang Yoo ${ }^{1,2}$, Seong-Joon Lee ${ }^{3}$, Jeong-Ho Hong ${ }^{1}$, Yong-Won Kim ${ }^{4}$, Ji Man Hong ${ }^{3}$, Chang-Hyun Kim5, Dong-Hun Kang ${ }^{6}$, Jin Wook Choi ${ }^{7}$, Yong-Sun Kim ${ }^{8}$, Sung-Il Sohn ${ }^{1}$, Yang-Ha Hwang ${ }^{4^{*}}$ and Jin Soo Lee ${ }^{3^{*}}$ (D)

\begin{abstract}
Background: Although stent retriever (SR) is recommended as a frontline device of endovascular treatment (EVT) for embolic large artery occlusion causing acute ischemic stroke, contact aspiration (CA) device showed similar efficacy in the recent trials. However, the efficacy of the both devices as first-line therapy for intracranial atherosclerotic stenosis (ICAS)-related large vessel occlusion has not yet been established. Therefore, we compared the immediate effects and final outcomes of SR and CA as first-line devices for treating ICAS-related occlusions.

Methods: We retrospectively analyzed the data of patients who underwent EVT for acute ischemic stroke from the registry of three Korean hospitals. Patients with ICAS-related occlusion who were treated within $24 \mathrm{~h}$ of onset of the symptoms were included. We investigated immediate reperfusion performance, immediate safety outcomes, and 3month clinical outcomes for the two first-line devices.

Results: Of the 720 registered patients, 111 were eligible for this study. Forty-nine patients (44.1\%) used SR and 62 (55.9\%) used CA as the first-line device. Achieving successful reperfusion immediately after first-line thrombectomy was more frequent in the SR group than that in the CA group $(77.6 \%$ vs. $43.5 \%, p=0.001)$, with fewer additional rescue treatments $(12.2 \%$ vs. $59.7 \%, p<0.001)$. The incidence of iatrogenic dissection or rupture was lower in the SR group than that in the CA group ( $8.2 \%$ vs. $29.0 \%, p=0.012)$. After additional rescue treatments, however, the final successful reperfusion rate did not differ between the two groups (SR $87.8 \%$ vs. CA 77.4\%, $p=0.247$ ), and there was no significant difference in the 3-month good outcomes (modified Rankin Scale, $p=0.524$ ).

\footnotetext{
* Correspondence: yangha.hwang@gmail.com; jinsoo22@gmail.com

${ }^{4}$ Department of Neurology, Kyungpook National University Hospital, School

of Medicine, Kyungpook National University, 130 Dongdeok-ro, Jung-gu,

Daegu 41944, South Korea

${ }^{3}$ Department of Neurology, Ajou University Medical Center, Ajou University

School of Medicine, 164 World cup-ro, Yeongtong-gu, Suwon 16499, South

Korea

Full list of author information is available at the end of the article
}

(c) The Author(s). 2020 Open Access This article is licensed under a Creative Commons Attribution 4.0 International License, which permits use, sharing, adaptation, distribution and reproduction in any medium or format, as long as you give appropriate credit to the original author(s) and the source, provide a link to the Creative Commons licence, and indicate if changes were made. The images or other third party material in this article are included in the article's Creative Commons licence, unless indicated otherwise in a credit line to the material. If material is not included in the article's Creative Commons licence and your intended use is not permitted by statutory regulation or exceeds the permitted use, you will need to obtain permission directly from the copyright holder. To view a copy of this licence, visit http://creativecommons.org/licenses/by/4.0/ The Creative Commons Public Domain Dedication waiver (http://creativecommons.org/publicdomain/zero/1.0/) applies to the data made available in this article, unless otherwise stated in a credit line to the data. 
(Continued from previous page)

Conclusions: First-line SR thrombectomy showed higher immediate reperfusion and less vessel injury for ICASrelated occlusions than CA. However, there was no significant difference in the final reperfusion status or 3-month outcomes from additional rescue treatments.

Keywords: Ischemic stroke, Reperfusion therapy, Stent retriever, Contact aspiration, Intracranial atherosclerosis, Endovascular treatment

\section{Background}

Endovascular treatment (EVT) has shown favorable results in major trials mainly using stent retriever (SR) [1]. Therefore, SR is recommended as a first-line device for treatment of large vessel occlusion in the AHA/ASA guidelines [2]. However, contact aspiration (CA) showed outcomes comparable to those with SR in recent studies [3, 4].

Intracranial atherosclerotic stenosis (ICAS)-related large vessel occlusion (ICAS-LVO) is a common cause of stroke, especially among the Asian population [5-9]. In ICAS-LVO, immediate reocclusion occurs frequently, requiring further rescue treatment, and the final reperfusion rate tends to be lower than that of embolic occlusions $[10,11]$. Because of these features, a different approach may be needed for ICAS-LVO than that for general embolic occlusions [12].

However, which device is suitable for first-line therapy in ICAS-LVO is unclear, because most of the previous randomized trials were based on Western populations. Knowledge about which device is more effective in ICAS-LVO would be useful in selecting a more suitable device for patients with ICAS-LVO before EVT [13-15]. Recently, a study comparing outcome of SR and CA in ICAS-LVO patients at two hospitals was published [16]. However, studies on immediate performances and side effects are still insufficient. Therefore, we compared the immediate effects and final outcomes of using SR or CA as first-line devices in the treatment of ICAS-LVO.

\section{Methods}

\section{Study population and inclusion criteria}

All clinical and image data were de-identified and allocated study identification numbers. The protocol for data collection was approved by the Institutional Review Board of each hospital. Our study was implemented in accordance with the ethical standards of the 1964 Declaration of Helsinki and its later amendments. The need for written informed consent was waived because of the retrospective nature of this study. The data of this study are available from the corresponding author upon reasonable request.

This was a retrospective analysis of the ASIAN KR (Acute Stroke due to Intracranial Atherosclerotic occlusion and Neurointervention Korean Retrospective) registry. The details of the registry were previously published
[11]. In brief, the registry consists of data on consecutive patients who underwent emergency EVT for cervicocerebral artery occlusions causing acute ischemic stroke at three stroke centers in Korea. The patients were enrolled between January 2011 and February 2016. For the current study, the inclusion criteria were: 1) patients with intracranial large artery occlusions; 2) underlying etiology classified as ICAS; and 3) time from symptom onset to EVT start $\leq 24 \mathrm{~h}$.

\section{Classifying ICAS-LVO}

Underlying ICAS, which should be differentiated from embolism or other etiologies, was defined based on the remaining fixed focal stenosis during EVT. The step-bystep evaluations for differentiation were described previously [11]. Briefly, after confirmation of arterial occlusion, patients with uncommon stroke etiologies, such as dissection, Moyamoya disease, and vasculitis were excluded. Embolic occlusion was classified based on complete vessel recanalization after thrombectomy, and ICAS-related occlusion was classified when a remnant stenosis of $>70 \%$, or a lesser degree of stenosis with a tendency toward reocclusion and/or flow impairment after thrombectomy was observed [11, 17]. This classification was further confirmed by repeat angiography during admission.

\section{EVT procedure}

Devices were selected at the discretion of neurointerventionists based on the consensus within each stroke team. In the current study, we divided patients into two groups based on whether SR or CA was used as the first-line device. Solitaire AB/FR (Medtronic, Irvine, CA, USA) or Trevo (Stryker, Kalamazoo, MI, USA) belonged to the SR group, and 1st generation or 2nd generation Penumbra MAX systems (Penumbra Inc., Alameda, CA, USA) belonged to the CA group. Balloon guide catheters, adjuvant local lytic infusion, intracranial angioplasty and/or stenting were implemented as needed.

\section{Image and clinical assessment}

Premorbid functional status, conventional vascular risk factors, and laboratory findings assessed during admission were collected. Stroke severity was assessed using 
the initial National Institutes of Health Stroke Scale (NIHSS) score. Clinical outcomes were measured using the modified Rankin Scale (mRS) score at 3-months. $\mathrm{mRS}$ scores 0 to 2 or no change between premorbid and 3-month mRS were considered as good outcomes.

The location of initial occlusion site was determined using baseline computed tomography angiography or magnetic resonance angiography. Reperfusion performance was evaluated using modified treatment in cerebral ischemia (mTICI) grade [18]. Successful reperfusion was defined as mTICI grade $2 \mathrm{~b}$ or higher. When the first-line device did not achieve the desired reperfusion status, rescue treatments were allowed, including other thrombectomy devices, fibrinolytics, angioplasty, and intracranial stenting. The number of EVT methods used until achievement of final reperfusion was also determined. Intracerebral hemorrhages were classified in accordance with the European Cooperative Acute Stroke Study criteria [19]. Subarachnoid hemorrhage (SAH) was classified using the modified Fisher scale [20].

\section{Primary outcomes}

Immediate reperfusion performance as a primary efficacy outcome was assessed immediately after the first attempt and full use of the first-line thrombectomy device, and final reperfusion status was assessed at the last angiography. We also assessed the immediate side effects, such as 1) vasospasm, 2) iatrogenic dissection or rupture by thrombectomy, and 3) new embolism in other vessels as primary safety outcomes. Angiographic lesions with surface irregularity or intimal flap were considered as iatrogenic vessel injuries.

\section{Statistical analysis}

Variables are expressed as mean \pm standard deviations, medians (interquartile ranges), or numbers (percentages), as statistically appropriate. We compared baseline characteristics, as well as clinical and imaging results between the SR and CA groups using chi-squared tests and independent Student's $t$-tests or Wilcoxon rank-sum tests, respectively. To determine the factors associated with good clinical outcome and iatrogenic dissection, we performed multivariate analyses after adjusting for age, sex, and variables with $p<0.1$ in the univariate analysis. $p$ values were two-tailed, and variables were considered significant at $p<0.05$. All statistical analyses were performed with $\mathrm{R}$ version 3.5.1 (http://www.R-project.org).

\section{Results}

\section{Baseline characteristics}

During the study period, 111 of the 720 registered patients were included in the current study (Fig. 1). Mean age of the included patients was $65.2 \pm 13.3$ years, and 70 patients (63.1\%) were men. Among them, 49 patients (44.1\%) belonged to the SR group, and 62 (55.9\%) to the CA group. Demographics and baseline characteristics of the patients between two groups did not differ (Table 1).

\section{Immediate effects following first-line thrombectomy}

Table 2 summarizes the comparative results regarding treatment. Successful reperfusion after first attempt of thrombectomy was not significantly different between the two groups (SR $28.6 \%$ vs. CA $17.7 \%, p=0.260$ ). Immediate successful reperfusion after first-line thrombectomy was achieved more frequently in the SR group (SR $77.6 \%$ vs. CA $43.5 \%, p=0.001$ ) (Fig. $2 \mathrm{a}$ ). Transient vasospasm occurred in four patients in the SR group (SR

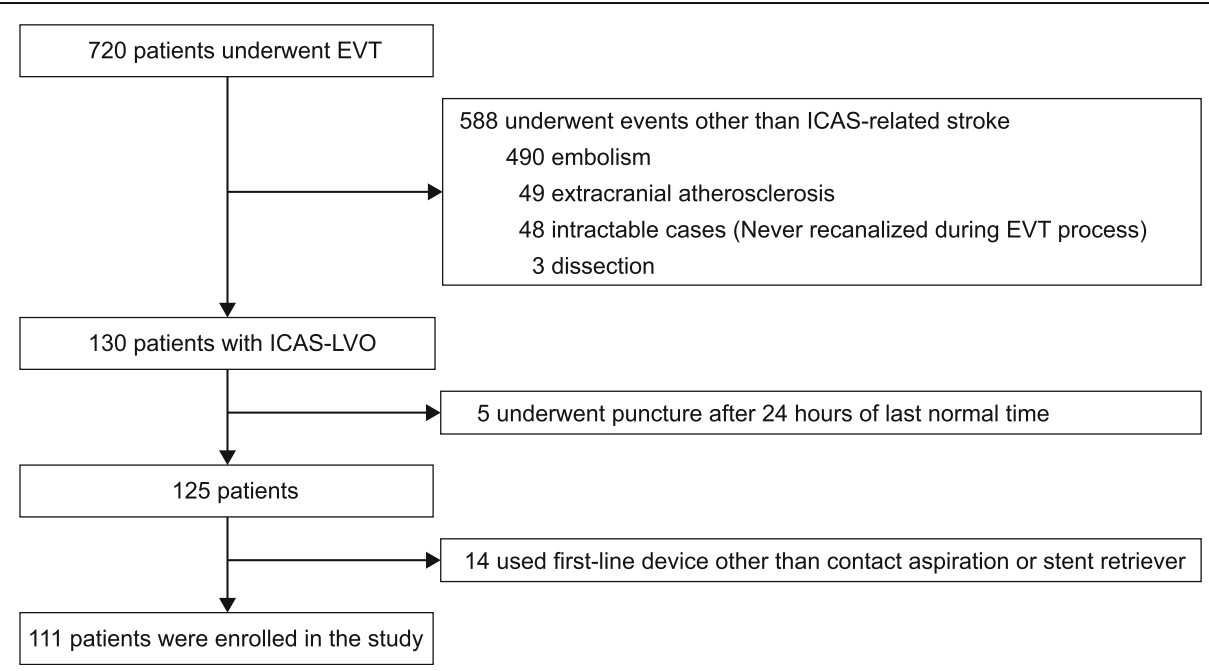

Fig. 1 Flowchart of the current study. EVT: Endovascular treatment; ICAS: Intracranial atherosclerotic stenosis; ICAS-LVO: ICAS-related large vessel occlusion 
Table 1 Baseline characteristics of patients with intracranial atherosclerotic stenosis (ICAS)-related occlusions and endovascular treatments

\begin{tabular}{|c|c|c|c|}
\hline & $\begin{array}{l}\text { Contact aspiration } \\
(n=62)\end{array}$ & $\begin{array}{l}\text { Stent retriever } \\
(n=49)\end{array}$ & $P$ \\
\hline \multicolumn{4}{|l|}{ Demographics } \\
\hline Age, years & $66.3 \pm 11.7$ & $63.9 \pm 15.2$ & 0.348 \\
\hline Sex, men & $39(62.9)$ & $31(63.3)$ & $>0.999$ \\
\hline \multicolumn{4}{|l|}{ Risk factors } \\
\hline Hypertension & $38(61.3)$ & $33(67.3)$ & 0.645 \\
\hline Diabetes mellitus & $20(32.3)$ & 14 (28.6) & 0.833 \\
\hline Dyslipidemia & $23(37.1)$ & $12(24.5)$ & 0.225 \\
\hline Atrial fibrillation & $14(22.6)$ & $10(20.4)$ & 0.965 \\
\hline Smoker & $26(41.9)$ & $13(25.5)$ & 0.103 \\
\hline \multicolumn{4}{|l|}{ Medications prior admission } \\
\hline Antiplatelets & $11(17.7)$ & $7(14.3)$ & 0.817 \\
\hline Anticoagulants & $2(3.2)$ & $4(8.2)$ & 0.403 \\
\hline Initial occlusion site & & & 0.078 \\
\hline Internal carotid artery & $12(19.4)$ & $2(4.1)$ & \\
\hline Middle cerebral artery, M1 & $36(58.1)$ & $36(73.5)$ & \\
\hline Middle cerebral artery, M2 & $2(3.2)$ & $1(2.0)$ & \\
\hline Vertebral artery & $2(3.2)$ & $4(8.2)$ & \\
\hline Basilar artery & $10(16.1)$ & $6(12.2)$ & \\
\hline Initial NIHSS score & $16.5(11-22)$ & $15(12-19)$ & 0.340 \\
\hline ASPECTS score ${ }^{a}$ & $7.5(5-9)$ & $7(6-8)$ & 0.625 \\
\hline \multicolumn{4}{|l|}{ Laboratory findings } \\
\hline Hemoglobin, g/dL & $14.0 \pm 1.8$ & $13.9 \pm 2.0$ & 0.764 \\
\hline White blood cells, $\times 10^{9} / \mathrm{L}$ & $9.6 \pm 3.6$ & $11.5 \pm 5.6$ & 0.047 \\
\hline Platelets, $\times 10^{9} / \mathrm{L}$ & $240 \pm 77$ & $239 \pm 59$ & 0.928 \\
\hline Glucose, mmol/L & $8.2 \pm 3.3$ & $8.4 \pm 3.3$ & 0.813 \\
\hline Intravenous tPA & $27(43.5)$ & $23(46.9)$ & 0.869 \\
\hline Use of balloon guide catheter & $36(58.1)$ & $26(53.1)$ & 0.738 \\
\hline Onset to door time, min & $208(111-387)$ & $172(105-560)$ & 0.801 \\
\hline Door to puncture time, min & $97.5(77-127)$ & $111(92-138)$ & 0.106 \\
\hline \multicolumn{4}{|l|}{ First-line thrombectomy device } \\
\hline Solitaire & & $41(83.7)$ & \\
\hline Trevo & & $8(16.3)$ & \\
\hline Penumbra, 1st generation & $45(72.6)$ & & \\
\hline Penumbra, 2nd generation & $17(27.4)$ & & \\
\hline
\end{tabular}

ICAS Intracranial atherosclerotic stenosis; NIHSS National Institutes of Health Stroke Scale; ASPECTS Alberta Stroke Program Early CT Score; tPA tissue plasminogen activator

${ }^{a}$ Baseline ASPECTS on quality imaging was evaluated in 81 patients (91.0\% patients with anterior circulation infarction)

$8.2 \%$ vs. CA $0 \%, p=0.035)$. In contrast, iatrogenic dissection or rupture occurred more frequently in the CA group (SR 8.2\% vs. CA 29.0\%, $p=0.012$ ). Odds ratio of iatrogenic dissection or rupture in the CA group was 4.488 in a logistic regression analysis after adjusting age, sex, presence of atrial fibrillation, initial NIHSS score, procedural time, and total number of EVT methods
(95\% confidence interval [CI] 1.394-17.676, $p=0.018$ ) (Supplementary Table 1). This rate of iatrogenic dissection or rupture was not different between the firstgeneration Penumbra and Penumbra MAX or between the Solitaire and Trevo stents; however, these results must be interpreted with caution owing to the small sample size. The frequency of new embolisms at other 
Table 2 Radiologic and clinical outcomes after endovascular treatment

\begin{tabular}{|c|c|c|c|}
\hline & $\begin{array}{l}\text { Contact aspiration } \\
(n=62)\end{array}$ & $\begin{array}{l}\text { Stent retriever } \\
(n=49)\end{array}$ & $P$ \\
\hline \multicolumn{4}{|l|}{ Immediate effects following first-line thrombectomy } \\
\hline Successful reperfusion after first attempt of thrombectomy & $11(17.7)$ & $14(28.6)$ & 0.260 \\
\hline Successful reperfusion after first-line thrombectomy & $27(43.5)$ & $38(77.6)$ & 0.001 \\
\hline \multicolumn{4}{|l|}{ Immediate side effect by first-line thrombectomy } \\
\hline Vasospasm & 0 & $4(8.2)$ & 0.035 \\
\hline latrogenic dissection or rupture & $18(29.0)$ & $4(8.2)$ & 0.012 \\
\hline New embolism in other vessels & $2(3.2)$ & $3(6.1)$ & 0.653 \\
\hline \multicolumn{4}{|l|}{ Rescue treatments after first-line thrombectomy } \\
\hline Switching to the other device & $37(59.7)$ & $6(12.2)$ & $<0.001$ \\
\hline Tirofiban infusion & $29(46.8)$ & $23(46.9)$ & $>0.999$ \\
\hline Balloon angioplasty & $7(11.3)$ & $5(10.2)$ & $>0.999$ \\
\hline Permanent intracranial stenting & $6(9.7)$ & $6(12.2)$ & 0.901 \\
\hline \multicolumn{4}{|l|}{ Final endovascular treatment results } \\
\hline Final successful reperfusion & $48(77.4)$ & $43(87.8)$ & 0.247 \\
\hline Total number of endovascular techniques & $2(2-3)$ & $2(1-2)$ & 0.003 \\
\hline Puncture to final angiography time, min & $76(48-116)$ & $63(45-92)$ & 0.151 \\
\hline \multicolumn{4}{|l|}{ Imaging and clinical outcomes after endovascular treatment } \\
\hline \multicolumn{4}{|l|}{ Hemorrhagic complication } \\
\hline Any intracerebral hemorrhagic transformation & $16(25.8)$ & $10(20.4)$ & 0.659 \\
\hline Parenchymal hemorrhage, type 2 & $2(3.2)$ & $4(8.2)$ & 0.403 \\
\hline $\mathrm{SAH}$, grade 3 or 4 & 0 & $2(4.1)$ & 0.193 \\
\hline Good outcome at 3 months & $23(37.1)$ & $22(44.9)$ & 0.524 \\
\hline
\end{tabular}

SAH Subarachnoid hemorrhage

vessels was relatively rare and did not differ between the groups (SR 6.1\% vs. CA 3.2\%, $p=0.653$ ).

\section{Rescue treatments after first-line thrombectomy}

The rate of switching to the other thrombectomy device (from SR to CA / from CA to SR) for rescue treatment was significantly lower in the SR group (SR $12.2 \%$ vs. CA $59.7 \%, p<0.001)$. As other rescue treatments, tirofiban infusion (SR $46.9 \%$ vs. CA $46.8 \%, p>0.999$ ), balloon angioplasty (SR $10.2 \%$ vs. CA $11.3 \%, p>0.999$ ), and permanent intracranial stenting (SR $12.2 \%$ vs. CA $9.7 \%, p=$ 0.901) were performed in both groups with no significant differences in their rates.

\section{Final endovascular treatment results}

Final successful reperfusion rate was similar between the two groups (SR $87.8 \%$ vs. CA $77.4 \%, p=0.247$ ) (Fig. 2b). However, the endovascular techniques were fewer in the SR group (SR $2[1,2]$ vs. CA $2[2,3], p=0.003$ ). Puncture to final angiography time was not significantly different (SR 76 [48-116] min vs. CA 63 [45-92] min, $p=0.151$ ).

\section{Imaging and clinical outcomes after endovascular treatment}

Intracerebral hemorrhagic transformation of any type $(p=0.659)$ and parenchymal hematoma type $2(p=$ 0.403 ) occurred at similar rates in the two groups. Thick subarachnoid hemorrhages occurred in two patients in the only SR group. There was no significant difference in good clinical outcome at 3 months (SR $44.9 \%$ vs. CA $37.1 \%, p=0.524$ ) (Fig. 2c). In multivariate analysis, 3month clinical outcome was not associated with the first-line thrombectomy device (Table 3). Instead, age, initial stroke severity, initial occlusion site and final successful reperfusion were independently associated with good clinical outcome at 3-months.

\section{Discussion}

In the current study, we investigated if there were differences primarily in immediate reperfusion performance and side effects, and secondarily in post-procedural hemorrhagic complications and clinical outcomes, depending on the choice of the first-line devices between SR and CA in patients with ICAS-LVO. Based on the results of our retrospective analysis of a multicenter 

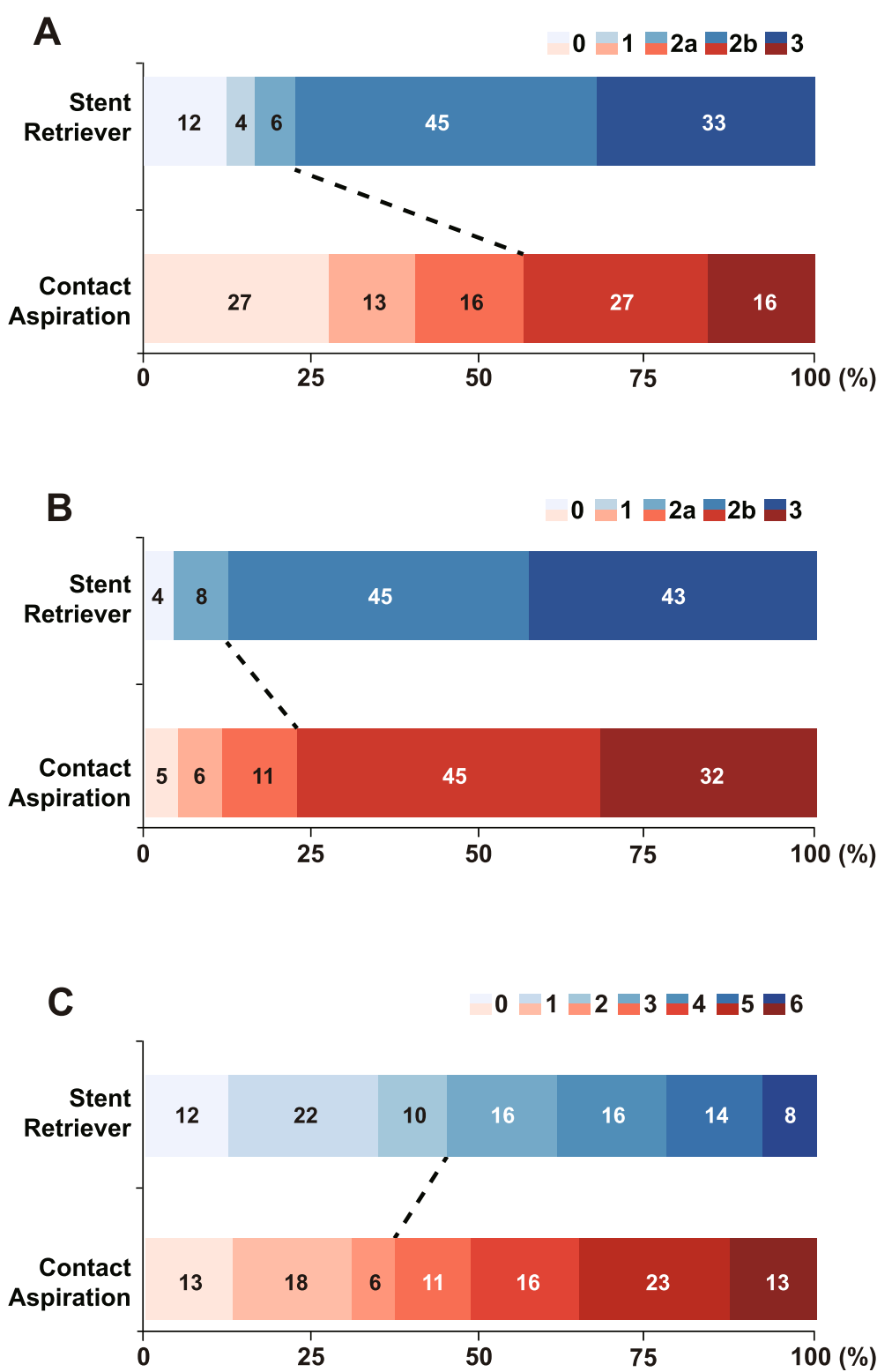

Fig. 2 Treatment outcomes. mTICl grade a immediately after first-line thrombectomy and $\mathbf{b}$ of final thrombectomy. c Modified Rankin Scale at 3 months. mTICl: modified thrombolysis in cerebral infarction

registry, we could cautiously mention that the use of SR may be safer and more effective for ICAS-LVO than CA as a first-line thrombectomy method in terms of immediate reperfusion success and immediate occurrence of iatrogenic dissection or rupture.

Recently, studies have reported comparisons of reperfusion performance or side effects of CA and SR when performing EVT in overall LVO patients. In the ASTER trial, the reperfusion success did not differ between CA and SR (mTICI score of $2 \mathrm{~b}$ or 3 , SR $67.7 \%$ vs. CA $63.0 \%$ ) $[3,21]$. More recently, the COMPASS trial showed that first-line CA treatment was not inferior to first-line SR treatment with respect to good outcomes (mRS 0-2, SR
$50 \%$ vs. CA $52 \%$;non-inferiority margin absolute difference $15 \% ; p_{\text {non-inferiority }}=0.0014$ ) [4]. The secondary angiographic outcomes did not significantly differ between groups but tended to be better in CA rather than in SR in terms of the median time to successful reperfusion (SR 33 min vs. CA $22 \mathrm{~min}, p=0.019$ ). These trials provide convincing evidence that $\mathrm{CA}$ may be used as an alternative to SR thrombectomy as first-line therapy in anterior circulation LVO-related acute ischemic stroke within $6 \mathrm{~h}$ of symptoms onset. However, these trials were performed in the Western countries (France, USA, and Canada), where the most predominant cause of emergency LVOs was known to be embolic occlusion. Large 
Table 3 Factors associated with good clinical outcome in patients with intracranial atherosclerotic stenosis (ICAS)-related occlusion

\begin{tabular}{|c|c|c|c|c|c|}
\hline & \multicolumn{3}{|c|}{ Univariate analysis } & \multicolumn{2}{|l|}{ Multivariate analysis } \\
\hline & $\begin{array}{l}\text { Poor outcome } \\
(N=66)\end{array}$ & $\begin{array}{l}\text { Good outcome } \\
(N=45)\end{array}$ & $P$ & Odds ratio $(95 \% \mathrm{Cl})$ & $P$ \\
\hline \multicolumn{6}{|l|}{ Demographics } \\
\hline Age, years & $68.7 \pm 11.9$ & $60.2 \pm 14.2$ & 0.001 & $0.956(0.915-0.995)$ & 0.035 \\
\hline Sex, men & $39(59.1)$ & $31(68.9)$ & 0.395 & $0.863(0.287-2.542)$ & 0.789 \\
\hline \multicolumn{6}{|l|}{ Risk factors } \\
\hline Hypertension & $46(69.7)$ & $25(55.6)$ & 0.186 & & \\
\hline Diabetes mellitus & $20(30.3)$ & $14(31.1)$ & $>0.999$ & & \\
\hline Dyslipidemia & $22(33.3)$ & $13(28.9)$ & 0.774 & & \\
\hline Atrial fibrillation & $12(18.2)$ & $12(26.7)$ & 0.406 & & \\
\hline Smoker & $20(30.3)$ & $19(42.2)$ & 0.276 & & \\
\hline Initial occlusion site & & & 0.001 & & \\
\hline Internal carotid artery & $13(19.7)$ & $1(2.2)$ & & Ref & \\
\hline Middle cerebral artery & $36(54.5)$ & $39(86.7)$ & & $12.544(1.777-259.986)$ & 0.030 \\
\hline Vertebral/Basilar artery & $17(25.8)$ & $5(11.1)$ & & $5.021(0.520-117.656)$ & 0.206 \\
\hline Initial NIHSS score & 19 (14-23) & $12(9-16)$ & $<0.001$ & $0.830(0.742-0.913)$ & $<0.001$ \\
\hline ASPECTS score ${ }^{a}$ & $7(4-8)$ & $8(6-10)$ & 0.005 & & \\
\hline Onset to door time, min & $196(120-421)$ & $204(82-457)$ & 0.833 & & \\
\hline Door to puncture time, min & $106(81-130)$ & $107(89-123)$ & 0.881 & & \\
\hline IV tPA & $30(45.5)$ & $20(44.4)$ & $>0.999$ & & \\
\hline Stent retriever as first-line device & $27(40.9)$ & $22(48.9)$ & 0.524 & $0.987(0.346-2.770)$ & 0.980 \\
\hline Primary successful reperfusion & $35(53.0)$ & $30(66.7)$ & 0.217 & & \\
\hline Final successful reperfusion & $51(77.3)$ & $40(88.9)$ & 0.190 & $5.479(1.441-24.841)$ & 0.018 \\
\hline Number of techniques & $2(2-3)$ & $2(1-3)$ & 0.457 & $1.208(0.643-2.293)$ & 0.555 \\
\hline \multicolumn{6}{|l|}{ Laboratory findings } \\
\hline Hemoglobin, g/dL & $14.0 \pm 1.9$ & $14.0 \pm 2.0$ & 0.917 & & \\
\hline White blood cells, $\times 10^{9} / \mathrm{L}$ & $11.2 \pm 5.0$ & $9.4 \pm 3.8$ & 0.036 & $0.910(0.784-1.039)$ & 0.186 \\
\hline Platelets, $\times 10^{9} / \mathrm{L}$ & $242 \pm 72$ & $236 \pm 65$ & 0.616 & & \\
\hline Glucose, $\mathrm{mmol} / \mathrm{L}$ & $8.2 \pm 3.1$ & $8.4 \pm 3.5$ & 0.709 & & \\
\hline
\end{tabular}

${ }^{a}$ Baseline ASPECTS on quality imaging was evaluated in 81 patients (91.0\% patients with anterior circulation infarction)

NIHSS National Institutes of Health Stroke Scale; ASPECTS Alberta Stroke Program Early CT Score; IV tPA Intravenous tissue plasminogen activator

artery atherosclerosis as the suspected cause of stroke accounted for around $7.9 \%$ in the ASTER trial [3], and $5.5 \%$ was reported in a retrospective study from France [22]. In contrast, ICAS as an underlying etiology of LVO is reported to be more frequent among the Asian populations (17.6-19.0\% based on most relevant methodology) $[9,11]$. Mechanical thrombectomy in a severe atherosclerotic arterial bed may have different performance and side effects because stenotic lesions can cause additional friction with devices [23]. It has been suggested that ICASLVO may require a different approach than embolic LVO $[8,9]$. Therefore, we evaluated if there were differences between SR and CA in terms of performance and side effects after first-line thrombectomy.

In the current study, immediate reperfusion performance was better when SR was used as a first-line device in ICAS-LVO. Therefore, rescue treatment involving the use of other devices was more common in the CA group, and the overall number of techniques was also higher with the use of CA. These results are consistent with those of the ASTER trial, in which rescue treatment after fist-line strategy tended to be more frequent in the CA group (32.8\%) than in SR group (23.8\%) with marginal statistical significance (3), and in a previously reported observational comparative study (CA $45.2 \%$ vs. SR 13.5\%) that showed statistical significance [24]. In the current study, as rescue techniques, the rates of tirofiban infusion, angioplasty, or stent insertion were similar between the two groups, whereas the switching rate from CA to SR was significantly higher in the CA group than that in the SR group. Although the successful reperfusion rate was higher in the SR group, there were no significant 
differences in rescue techniques such as tirofiban infusion, suggesting that ICAS-LVO tends to reocclusion and still requires additional treatment in many patients.

Among the immediate side effects, the frequency of iatrogenic dissection or rupture appeared to be prominent. Mechanical thrombectomy may cause vessel damage [25-28]. Several animal studies have shown occurrence of intima and medial damage after thrombectomy using SR or CA devices. Some of the vessel damage could be transient, but some could leave long-term damage [26]. Despite these natural characteristics of mechanical thrombectomy, the occurrence rate of iatrogenic dissection or rupture in both groups of the current study was higher than that that of recent trials reported in Western countries. In the ASTER trial, the frequency of arterial dissection was only $1.1 \%$ (SR group) to $2.6 \%$ (CA group) (3). More frequent vessel injury in our study might be caused by vessel stenosis. When outcomes were compared between ICAS- and embolic LVOs with Solitaire stent thrombectomy, the frequency of vessel injury using the same definition as the current study accounted for $13.5 \%$ vs. $3.7 \%$, respectively [29]. In addition, immediate vessel injury was more frequent in the CA group than in SR group in the current study. In general, SR is expected to have more vessel injury than CA. However, ICAS can make the tip of $\mathrm{CA}$ catheter more difficult to face thrombus due to hurdle-like anatomy of stenotic lumens. A recent review article attributes this phenomenon to the possibility that the tip of aspiration catheter may not properly contact the in situ thrombi but may face the surface of ICAS [30].

Even though rescue treatments were more frequently used and procedural time was longer in the CA group than in SR group, final reperfusion success and 3-month good outcome did not differ. Taken together, SR can be considered more advantageous as a first-line device than CA for treatment of ICAS-LVO. However, despite this immediate advantage, there was no significant difference in the outcome following aggressive rescue treatment and device switching [31, 32].

Despite of the differences of immediate reperfusion performance and side effect, there was no difference in the final outcome. The difference in the outcome of the firstline treatment may be complemented by the rescue treatment, but the effect of post-procedure management cannot be denied. Because the purpose of this study is not related to this, we could not present relevant data, but the followings could be considered. While lowering blood pressure when reperfusion after embolic occlusion is recommended to prevent reperfusion injury, maintaining blood pressure slightly higher for remnant stenosis would be helpful to maintain cerebral perfusion pressure in patients with ICAS. In addition, as shown in SAMMPRIS trial, we should consider maintaining sufficient antithrombotic activity with dual antiplatelets at least the first 3 months and use of intensive statin in anticipation of regression of stenosis [33, 34]. Further studies are needed on the post-procedure management with ICAS patients.

This study has several limitations. First, this was a retrospective study; therefore, it is not free from selection bias. Second, patients who were enrolled early in the study period in the registry underwent treatment with outdated devices, such as the first-generation Penumbra that are not currently in use. Moreover, new CA devices have been commercialized recently, and further studies on their effects and safety are needed. To this point, we also compared the first-generation and subsequent Penumbra systems but there was no difference in terms of outcomes (data not shown). In addition, future research may be required as new techniques such as Solumbra or stent retriever assisted vacuum-locked extraction have been introduced. Third, while we tried our best to distinguish underlying ICAS from vessel injury after EVT, it might be difficult to distinguish them completely, which can lead to errors. Nevertheless, because these errors were applied to both groups equally, there would be no significant bias in comparing the results. Finally, in this study, the device was selected based on the practitioner's personal preference, and there could be a bias because this was not a randomized trial. Despite these limitations, our study may be helpful in selecting devices in patients who are predicted to have ICAS-LVO [13-15].

\section{Conclusions}

First-line SR thrombectomy showed higher immediate reperfusion and lesser vessel injury than CA for ICASrelated occlusions. However, there was no significant difference in the final reperfusion status or 3-month outcomes from additional rescue treatments. Our study may be useful for device selection in ICAS-LVO patients and warrants future large-scale prospective studies.

\section{Supplementary information}

Supplementary information accompanies this paper at https://doi.org/10. 1186/s12883-020-01862-6.

Additional file 1: Supplemental Table 1. Multivariate analysis according to iatrogenic dissection or rupture. Supplementary figure. (A) The first patient shows flap in the right middle cerebral artery. We detached stent retriever because of recurrent occlusion after retrieving stent retriever. (B) and (C) The second and third patients show intima flap in the left middle cerebral artery after contact aspiration and (D) The fourth patient shows intima flap in the left middle cerebral artery after retrieving stent retriever.

\section{Abbreviations}

CA: Contact aspiration; EVT: Endovascular treatment; ICAS: Intracranial atherosclerotic stenosis; ICAS-LVO: Intracranial atherosclerosis-related large vessel occlusion; mRS: modified Rankin scale; $\mathrm{mTICl}$ : modified treatment in cerebral ischemia; NIHSS: National Institutes of Health Stroke Scale; SR: Stent retriever 


\section{Acknowledgements}

None.

\section{Authors' contributions}

Study design J.Y., J.S.L.; data collection J.Y., S.-J.L., J.-H.H., Y.-W.K., J.M.H., C.-H.K., D.-H.K., J.W.C., Y.-S.K., S.I.S., Y.-H.H., J.S.L.; data analysis J.Y., J.S.L.; data interpretation J.Y., J.S.L.; preparation of the manuscript J.Y., J.S.L.; review and editing J.Y., S.-J.L., J.-H.H., Y.-W.K., J.M.H., C.-H.K., D.-H.K., J.W.C., Y.-S.K., S.-I.S., Y.H.H., J.S.L. All authors have read and approved the final version of manuscript.

\section{Funding}

This study was partly supported by the National Research Foundation of Korea Grant funded by the Korean government (NRF-2018R1A2B6007094 and MSIP No. 2014R1A5A2010008). The funder had no role in the design, patient collection, data analysis, interpretation of data, and writing the manuscript.

\section{Availability of data and materials}

The data of this study are available from the corresponding author upon reasonable request.

\section{Ethics approval and consent to participate}

The protocol for data collection was approved by the Institutional Review Board (IRB) of each hospital (Ajou University hospital's IRB: AJIRB-MED-OBS15-483, Kyungpook National University hospital's IRB: 2016-01-020, Keimyung University Dongsan hospital's IRB: 2016-01-038-10). Our study was implemented in accordance with the ethical standards of the 1964 Declaration of Helsinki and its later amendments. The need for written informed consent was waived because of the retrospective nature of this study.

\section{Consent for publication}

Not applicable.

\section{Competing interests}

The authors declare that they have no competing interests.

\section{Author details}

'Department of Neurology, Keimyung University School of Medicine, Daegu, South Korea. ${ }^{2}$ Department of Neurology, National Health Insurance Service Ilsan Hospital, Goyang, South Korea. ${ }^{3}$ Department of Neurology, Ajou University Medical Center, Ajou University School of Medicine, 164 World cup-ro, Yeongtong-gu, Suwon 16499, South Korea. ${ }^{4}$ Department of Neurology, Kyungpook National University Hospital, School of Medicine, Kyungpook National University, 130 Dongdeok-ro, Jung-gu, Daegu 41944, South Korea. ${ }^{5}$ Department of Neurosurgery, Keimyung University School of Medicine, Daegu, South Korea. ${ }^{6}$ Department of Neurosurgery, Kyungpook National University School of Medicine, Daegu, South Korea. ${ }^{7}$ Department of Radiology, Ajou University School of Medicine, Suwon, South Korea. ${ }^{8}$ Department of Radiology, Kyungpook National University School of Medicine, Daegu, South Korea.

Received: 6 April 2020 Accepted: 12 July 2020

Published online: 18 July 2020

\section{References}

1. Goyal M, Menon BK, van Zwam WH, Dippel DW, Mitchell PJ, Demchuk AM, et al. Endovascular thrombectomy after large-vessel ischaemic stroke: a meta-analysis of individual patient data from five randomised trials. Lancet. 2016;387(10029):1723-31. https://doi.org/10.1016/s0140-6736(16)00163-x.

2. Powers WJ, Rabinstein AA, Ackerson T, Adeoye OM, Bambakidis NC, Becker $K$, et al. Guidelines for the early Management of Patients with Acute Ischemic Stroke: 2019 update to the 2018 guidelines for the early Management of Acute Ischemic Stroke: a guideline for healthcare professionals from the American Heart Association/American Stroke Association. Stroke. 2019;50(12):e344-418. https://doi.org/10.1161/str 0000000000000211

3. Lapergue B, Blanc R, Gory B, Labreuche J, Duhamel A, Marnat G, et al. Effect of endovascular contact aspiration vs stent retriever on revascularization in patients with acute ischemic stroke and large vessel occlusion: the ASTER randomized clinical trial. JAMA. 2017;318(5):443-52. https://doi.org/10.1001/ jama.2017.9644.

4. Turk AS 3rd, Siddiqui A, Fifi JT, De Leacy RA, Fiorella DJ, Gu E, et al. Aspiration thrombectomy versus stent retriever thrombectomy as first-line approach for large vessel occlusion (COMPASS): a multicentre, randomised, open label, blinded outcome, non-inferiority trial. Lancet. 2019;393(10175): 998-1008. https://doi.org/10.1016/s0140-6736(19)30297-1.

5. Kim JS, Bonovich D. Research on intracranial atherosclerosis from the east and west: why are the results different? J Stroke. 2014;16(3):105-13. https:// doi.org/10.5853/jos.2014.16.3.105

6. Toyoda K, Koga M, Hayakawa M, Yamagami H. Acute reperfusion therapy and stroke care in Asia after successful endovascular trials. Stroke. 2015; 46(6):1474-81. https://doi.org/10.1161/strokeaha.115.008781.

7. Bang OY. Considerations when subtyping ischemic stroke in Asian patients. J Clin Neurol. 2016;12(2):129-36. https://doi.org/10.3988/jcn.2016.12.2.129.

8. Lee JS, Hong JM, Kim JS. Diagnostic and therapeutic strategies for acute intracranial atherosclerosis-related occlusions. J Stroke. 2017;19(2):143-51. https://doi.org/10.5853/jos.2017.00626.

9. Baek JH, Kim BM, Heo JH, Kim DJ, Nam HS, Kim YD. Outcomes of endovascular treatment for acute intracranial atherosclerosis-related large vessel occlusion. Stroke. 2018:49(11):2699-705. https://doi.org/10.1161/ strokeaha.118.022327.

10. Hwang YH, Kim YW, Kang DH, Kim YS, Liebeskind DS. Impact of target arterial residual stenosis on outcome after endovascular revascularization. Stroke. 2016;47(7):1850-7. https://doi.org/10.1161/strokeaha.116.013046.

11. Lee JS, Lee SJ, Yoo JS, Hong JH, Kim CH, Kim YW, et al. Prognosis of acute intracranial atherosclerosis-related occlusion after endovascular treatment. J Stroke. 2018;20(3):394-403. https://doi.org/10.5853/jos.2018.01627.

12. Kang $\mathrm{DH}$, Yoon W. Current opinion on endovascular therapy for emergent large vessel occlusion due to underlying intracranial atherosclerotic stenosis. Korean J Radiol. 2019;20(5):739-48. https://doi.org/10.3348/kjr.2018.0809.

13. Ryu CW, Kwak HS, Jahng GH, Lee HN. High-resolution MRI of intracranial atherosclerotic disease. Neurointervention. 2014;9(1):9-20. https://doi.org/10. 5469/neuroint.2014.9.1.9.

14. Baek JH, Kim BM, Yoo J, Nam HS, Kim YD, Kim DJ, et al. Predictive value of computed tomography angiography-determined occlusion type in stent retriever Thrombectomy. Stroke. 2017;48(10):2746-52. https://doi.org/10. 1161/strokeaha.117.018096.

15. Baek JH, Kim BM. Angiographical identification of intracranial, atherosclerosis-related, Large Vessel Occlusion in Endovascular Treatment. Front Neurol. 2019;10:298. https://doi.org/10.3389/fneur.2019.00298.

16. Kang DH, Yoon W, Baek BH, Kim SK, Lee YY, Kim JT, et al. Front-line thrombectomy for acute large-vessel occlusion with underlying severe intracranial stenosis: stent retriever versus contact aspiration. J Neurosurg. 2019:1-7. https://doi.org/10.3171/2019.1.Jns182905.

17. Kim YW, Hong JM, Park DG, Choi JW, Kang DH, Kim YS, et al. Effect of intracranial atherosclerotic disease on endovascular treatment for patients with acute Vertebrobasilar occlusion. AJNR Am J Neuroradiol. 2016;37(11): 2072-8. https://doi.org/10.3174/ajnr.A4844.

18. Tomsick T, Broderick J, Carrozella J, Khatri P, Hill M, Palesch Y, et al. Revascularization results in the interventional Management of Stroke II trial. AJNR Am J Neuroradiol. 2008;29(3):582-7. https://doi.org/10.3174/ ajnr.A0843.

19. Fiorelli M, Bastianello S, von Kummer R, del Zoppo GJ, Larrue V, Lesaffre E, et al. Hemorrhagic transformation within 36 hours of a cerebral infarct: relationships with early clinical deterioration and 3-month outcome in the European cooperative acute stroke study I (ECASS I) cohort. Stroke. 1999; 30(11):2280-4.

20. Frontera JA, Claassen J, Schmidt JM, Wartenberg KE, Temes R, Connolly ES $\mathrm{Jr}$, et al. Prediction of symptomatic vasospasm after subarachnoid hemorrhage: the modified fisher scale. Neurosurgery. 2006;59(1):21-7; discussion -7. https://doi.org/10.1227/01.Neu.0000218821.34014.1b.

21. Lapergue B, Labreuche J, Blanc R, Barreau X, Berge J, Consoli A, et al. Firstline use of contact aspiration for thrombectomy versus a stent retriever for recanalization in acute cerebral infarction: the randomized ASTER study protocol. Int J Stroke. 2018;13(1):87-95. https://doi.org/10.1177/ 1747493017711948

22. Gascou G, Lobotesis K, Machi P, Maldonado I, Vendrell JF, Riquelme C et al. Stent retrievers in acute ischemic stroke: complications and failures during the perioperative period. AJNR Am J Neuroradiol. 2014;35(4):734-40. https:/ doi.org/10.3174/ajnr.A3746. 
23. Yin NS, Benavides S, Starkman S, Liebeskind DS, Saver JA, Salamon N, et al. Autopsy findings after intracranial thrombectomy for acute ischemic stroke: a clinicopathologic study of 5 patients. Stroke. 2010;41(5):938-47. https:// doi.org/10.1161/strokeaha.109.576793.

24. Lapergue B, Blanc R, Guedin P, Decroix JP, Labreuche J, Preda C, et al. A direct aspiration, first pass technique (ADAPT) versus stent retrievers for acute stroke therapy: an observational comparative study. AJNR Am J Neuroradiol. 2016;37(10):1860-5. https://doi.org/10.3174/ajnr.A4840.

25. Nogueira RG, Levy El, Gounis M, Siddiqui AH. The Trevo device: preclinical data of a novel stroke thrombectomy device in two different animal models of arterial thrombo-occlusive disease. J Neurointerv Surg. 2012;4(4):295-300. https://doi.org/10.1136/neurintsurg-2011-010053.

26. Kurre W, Perez MA, Horvath D, Schmid E, Bazner H, Henkes H. Does mechanical thrombectomy in acute embolic stroke have long-term side effects on intracranial vessels? An angiographic follow-up study. Cardiovasc Intervent Radiol. 2013;36(3):629-36. https://doi.org/10.1007/s00270-0120496-8.

27. Gory B, Bresson D, Kessler I, Perrin ML, Guillaudeau A, Durand K, et al. Histopathologic evaluation of arterial wall response to 5 neurovascular mechanical thrombectomy devices in a swine model. AJNR Am J Neuroradiol. 2013;34(11):2192-8. https://doi.org/10.3174/ajnr.A3531.

28. Arai D, Ishii A, Chihara H, Ikeda H, Miyamoto S. Histological examination of vascular damage caused by stent retriever thrombectomy devices. J Neurointerv Surg. 2016;8(10):992-5. https://doi.org/10.1136/neurintsurg2015-011968.

29. Lee JS, Lee SJ, Hong JM, Choi JW, Yoo J, Hong JH, et al. Solitaire Thrombectomy for acute stroke due to intracranial atherosclerosis-related occlusion: ROSE ASSIST study. Front Neurol. 2018;9:1064. https://doi.org/10. 3389/fneur.2018.01064.

30. Kang DH, Hwang YH. Frontline contact aspiration treatment for emergent large vessel occlusion: a review focused on practical techniques. I Stroke. 2019;21(1):10-22. https://doi.org/10.5853/jos.2018.03076.

31. Kang DH, Yoon W, Kim SK, Baek BH, Lee YY, Kim YW, et al. Endovascular treatment for emergent large vessel occlusion due to severe intracranial atherosclerotic stenosis. J Neurosurg. 2018:1-8. https://doi.org/10.3171/2018. 1.Jns 172350

32. Chang Y, Kim BM, Bang OY, Baek JH, Heo JH, Nam HS, et al. Rescue stenting for failed mechanical Thrombectomy in acute ischemic stroke: a multicenter experience. Stroke. 2018:49(4):958-64. https://doi.org/10.1161/strokeaha.117. 020072

33. Chimowitz MI, Lynn MJ, Derdeyn CP, Turan TN, Fiorella D, Lane BF, et al. Stenting versus aggressive medical therapy for intracranial arterial stenosis. N Engl J Med. 2011;365(11):993-1003. https://doi.org/10.1056/ NEJMoa1105335.

34. Kim JS, Bang OY. Medical treatment of intracranial atherosclerosis: an update. J Stroke. 2017:19(3):261-70. https://doi.org/10.5853/jos.2017.01830.

\section{Publisher's Note}

Springer Nature remains neutral with regard to jurisdictional claims in published maps and institutional affiliations.

Ready to submit your research? Choose BMC and benefit from:

- fast, convenient online submission

- thorough peer review by experienced researchers in your field

- rapid publication on acceptance

- support for research data, including large and complex data types

- gold Open Access which fosters wider collaboration and increased citations

- maximum visibility for your research: over $100 \mathrm{M}$ website views per year

At $\mathrm{BMC}$, research is always in progress.

Learn more biomedcentral.com/submissions 